REVISTA DE DERECHO UNED, NÚM. 14, 2014

\title{
RECONOCIMIENTO DE LA TITULARIDAD Y EL EJERCICIO DE LOS DERECHOS CIVILES Y POLÍTICOS DE LOS RESIDENTES LATINOAMERICANOS EN ESPAÑA. EL DERECHO AL SUFRAGIO EN ELECCIONES LOCALES
}

\author{
CIVIL AND POLITICAL RIGHTS OF LATIN AMERICAN \\ RESIDENTS IN SPAIN. THE RIGHT TO VOTE IN LOCAL \\ ELECTIONS
}

\author{
Yolanda Carmela Vaccaro Alexander \\ www.yolandavaccaro.com \\ @yolandavaccaro
}

Doctoranda Departamento de Sociología I.

Facultad de Ciencias Políticas y Sociología. UNED.

Resumen: los ciudadanos latinoamericanos que residen en España disfrutan de un marco legal diferenciado respecto de lo que atañe a los residentes procedentes de otras zonas en el marco de los lazos históricos y culturales que unen España y Latinoamérica reflejados en la legislación española. España mantiene suscritos convenios de Doble Nacionalidad con la mayor parte de países latinoamericanos. Y, desde 2009, ha suscrito tratados de reciprocidad en materia de sufragio en elecciones locales con diferentes países, la mayor parte de ellos latinoamericanos, tratados que permitieron que en las elecciones locales celebradas en España el 22 de mayo de 2011 los latinoamericanos concernidos pudieran ejercer el derecho al voto activo en España por primera vez sin necesidad de haberse acogido a los mencionados convenios de Doble Nacionalidad. La encuesta "Ciudadanía inmigrante», analizada en este artículo y realizada para la tesis doctoral «Derechos civiles y políticos de los resi- 
dentes latinoamericanos en España. El derecho de sufragio», de la doctoranda autora de este artículo, da pautas sobre la percepción de los latinoamericanos residentes en España en torno a los derechos civiles y políticos y sobre su comportamiento respecto de los citados comicios de 2011.

Palabras clave: derechos civiles y políticos de los extranjeros en España; derechos de los latinoamericanos en España; sufragio de los latinoamericanos en España; convenios de reciprocidad en materia de sufragio.

Abstract: Latin American citizens residing in Spain enjoy a distinct legal framework compared to other foreign residents. That difference is based on the historical and cultural relations between Spain and Latin America. Spain has agreements on dual nationality with most Latin American countries. Starting in 2009 Spain has signed several reciprocity agreements about the right to vote in local elections with several countries, most of them in Latin America. On May 22, 2011 many Latin American citizens residing in Spain could exercise their right to vote in the Spanish local elections for the first time without having dual citizenship. The «Immigrant Citizenship» survey, analyzed in this article and developed for the doctoral thesis "Civil and Political Rights of Latin American Residents in Spain. The right to vote», provides guidance on the perception of Latin American living in Spain about civil and political rights and their behavior with respect to said elections.

Keywords: civil and political rights of foreigners in Spain; rights of Latin Americans in Spain; Latin American vote in Spain; reciprocity agreements to vote.

Recepción original:10/04/2014

Aceptación original: 16/05/2014

Sumario: I. Introducción. II. Delimitación conceptual de los derechos civiles y políticos. III. Marco legal correspondiente a los residentes latinoamericanos en España. 1. La Constitución Española y los tratados internacionales. 2. Tratados de reciprocidad en materia de sufragio en elecciones locales suscritos con países latinoamericanos. IV. Los latinoamericanos y las elecciones en España. 1. Percepción de los derechos civiles y políticos y comportamiento electoral por parte de los inmigrantes latinoamericanos frente a otro tipo de derechos. Opinión sobre la actitud de la Administración. 2. Valoración de los partidos políticos. Partidos políticos formados por inmigrantes. Intención de voto. 3 . El voto de los inmigrantes latinoamericanos en elecciones en España. La experiencia de las elecciones del 22 de mayo de 2011. V. Conclusiones. 


\section{INTRODUCCIÓN}

La inmigración latinoamericana en España se caracteriza por la mayor facilidad de su integración en virtud de su inherente procedencia histórica y cultural entroncada con España. En consonancia con ello los latinoamericanos en España cuentan con un estatus particular en cuanto al disfrute de derechos civiles y políticos respecto del resto de inmigrantes. Una actitud que avala la opinión pública mayoritaria dados los especiales vínculos hispano-latinoamericanos ${ }^{1}$.

En este marco y por reciprocidad la mayor parte de países latinoamericanos tienen suscritos con España convenios de Doble Nacionalidad $^{2}$. Conforme al Código Civil y al conjunto de la legislación pertinente del Ordenamiento Jurídico Español, los latinoamericanos cuyos países mantienen con España este tipo de convenios pueden solicitar acogerse a ellos una vez que llevan residiendo en España al menos dos años y sin interrupción ${ }^{3}$. España también mantiene suscritos convenios con los países latinoamericanos en otros ámbitos como el de la Seguridad Social ${ }^{4}$.

Profundizando en la suscripción de convenios emanados de las especiales relaciones entre España y Latinoamérica, desde 2009 España ha firmado tratados de reciprocidad con diferentes países, la mayor parte de ellos latinoamericanos, mediante los que los inmigrantes

${ }^{1}$ Según el estudio «Transatlantic Trends Inmigration», Informe de Resultados 2010, de The German Marshall Fund of the United States, pág. 33, el 62\% de la población en España opina que los inmigrantes legales deberían tener derecho al voto en comicios locales.

${ }^{2}$ España tiene suscritos convenios de Doble Nacionalidad con Andorra, Argentina, Bolivia, Brasil, Chile, Colombia, Costa Rica, Cuba, República Dominicana, Guinea Ecuatorial, Ecuador, Filipinas, Guatemala, Honduras, México, Nicaragua, Panamá, Paraguay, Perú, Portugal, Puerto Rico, El Salvador, Uruguay y Venezuela. Se encuentran detallados en la página web del MINISTERIO DE JUSTICIA: http://www. mjusticia.gob.es/cs/Satellite/es/1215198282690/EstructuraOrganica.html.

${ }^{3}$ CÓDIGO CIVIL ESPAÑOL. Artículo 22 puntos 1, 3 y 4:

1. Para la concesión de la nacionalidad por residencia se requiere que ésta haya durado diez años. Serán suficientes cinco años para los que hayan obtenido la condición de refugiado y dos años cuando se trate de nacionales de origen de países iberoamericanos, Andorra, Filipinas, Guinea Ecuatorial o Portugal o de sefardíes.

3. En todos los casos, la residencia habrá de ser legal, continuada e inmediatamente anterior a la petición.

4. El interesado deberá justificar, en el expediente regulado por la legislación del Registro Civil, buena conducta cívica y suficiente grado de integración en la sociedad española.

${ }^{4}$ El contenido de estos convenios consta en la página web del Instituto Nacional de Seguridad Social: http://www.seg-social.es/Internet_1/Masinformacion/Internacional/Conveniosbilaterales/index.htm. 
de dichos países pueden ejercer el derecho al voto ${ }^{5}$ aunque no se hayan acogido a los mencionados convenios de Doble Nacionalidad. Hablamos del voto en elecciones locales conforme marca la Constitución Española $(\mathrm{CE})^{6}$.

Para analizar la vinculación entre el citado marco legal y la percepción que sobre ella tienen los residentes latinoamericanos en España así como para estudiar el grado de puesta en práctica y ejercicio de la titularidad de los mencionados derechos por parte de sus titulares, este artículo utiliza como herramienta en su segunda parte la encuesta «Ciudadanía inmigrante».

Este trabajo se distribuye en dos bloques fundamentales. El primero se dedica a la legislación y al marco jurídico existente en torno a los derechos civiles y políticos de los inmigrantes en España, particularmente de los latinoamericanos. El segundo bloque da cuenta del ejercicio de tales derechos por parte de los ciudadanos titulares correspondientes.

\section{DELIMITACIÓN CONCEPTUAL DE LOS DERECHOS CIVILES Y POLÍTICOS}

Diferentes son los criterios de los juristas al delimitar el concepto de derechos civiles y políticos con una definición estricta. Así, el profesor Antonio Torres del Moral $^{7}$ señala: «Sólo recientemente los países jurídica y políticamente más avanzados adoptaron estándares mínimos de derechos para los extranjeros reconociéndoles, al menos, los que se entiende que corresponden a todas las personas. Actualmente ese nivel mínimo -lo que se ha llamado «estándar mínimo internacional»- coincide, según la profesora Elisa Pérez Vera, con la Declaración Universal de Derechos Humanos, aprobada por la ONU en 1948». Añade: «La tendencia internacional es la de ir ampliando los

${ }^{5}$ JUNTA ELECTORAL CENTRAL. Acuerdos internacionales relativos al Derecho de Sufragio en elecciones municipales: http://www.juntaelectoralcentral.es/portal/ page/portal/JuntaElectoralCentral/JuntaElectoralCentral/NormElec\#extranjeros

${ }^{6}$ CONSTITUCIÓN ESPAÑOLA. Artículo 13.2: Solamente los españoles serán titulares de los derechos reconocidos en el artículo 23, salvo lo que, atendiendo a criterios de reciprocidad, pueda establecerse por tratado o ley para el derecho de sufragio activo y pasivo en las elecciones municipales. Artículo 23.1: Los ciudadanos tienen el derecho a participar en los asuntos públicos, directamente o por medio de representantes, libremente elegidos en elecciones periódicas por sufragio universal.

7 TORRES DEL MORAL, Antonio. Principios de derecho constitucional español. Tomo I: Sistemas de fuentes. Sistema de los derechos. Universidad Complutense de Madrid, 2010. 
derechos y las garantías de los extranjeros ${ }^{8}$ reconociéndoles los derechos civiles y, en ocasiones, bajo ciertas circunstancias, también los derechos políticos» ${ }^{9}$.

La Ley Orgánica sobre Derechos y Libertades de los Extranjeros en España y su Integración Social, más conocida como Ley de Extranjería, en sus dos redacciones del año 2000 (leyes 4/2000 y 8/2000), que desarrolla el marco jurídico de los extranjeros en España, así como en su última modificación mediante Ley Orgánica 8/2009, de 11 de diciembre, delimita de manera elemental el marco jurídico de todos los extranjeros. La STC 36/2007, de 7 de noviembre $^{10}$, desarrolla las libertades públicas de las que gozan los extranjeros de reunión, manifestación, asociación y sindicación e incluso el derecho a la enseñanza gratuita obligatoria aunque la entrada en el país haya sido irregular. La participación política está regulada en un marco genérico por la LO 8/2009 ${ }^{11}$. En torno al derecho de sufragio,

${ }^{8}$ ANDRÉS, Hervé, «El derecho de voto de los extranjeros en el ámbito universal», Revista de Derecho Migratorio y Extranjería, n. ${ }^{\circ} 18,2008$, pág. 25. El autor apunta: «La tendencia global se dirige hacia el reconocimiento de ciertos derechos políticos a los extranjeros». Añade que «alrededor de un tercio de los Estados del mundo no limitan el derecho de voto exclusivamente a sus nacionales».

${ }^{9}$ FERNÁNDEZ ROZAS, José Carlos, «Extranjería: principios de derecho internacional general», Revista de Economía y Sociología del Trabajo, n. ${ }^{\circ} 11$, marzo de 1991, págs. 39-51. Para el autor el principio del trato mínimo internacional «es una noción acuñada por el Derecho internacional que faculta al Estado de donde es nacional un individuo para reclamar ante un país extranjero si la normativa de este último no es conforme a un estándar mínimo internacional. Dicho principio, si bien cuenta hoy con indiscutible vigencia, resulta de difícil precisión en cuanto a su contenido. Nadie duda que comprende los supuestos de muerte, prisión, malos tratos, detención prolongada, etc., de los extranjeros, pero en ciertos casos su alcance es controvertido. Así, por ejemplo, en relación con las nacionalizaciones de bienes extranjeros, las diferencias entre países desarrollados y países subdesarrollados o, si se quiere, entre países inversores y países receptores de capital, puede traer como consecuencia que, en estricta aplicación del principio, los extranjeros lleguen a alcanzar un estatuto superior al de los propios nacionales. Ello iría contra el postulado de la igualdad de trato".

${ }^{10}$ La STC236/2007, de 7 de noviembre, en resumen, declaró inconstitucionales preceptos de la LO 4/2000 - posteriormente modificada conforme a lo dictaminado por el TC por la LO 8/2009, de 11 de diciembre- y reconoció a todos los extranjeros la titularidad de los derechos a la asistencia jurídica gratuita, a la educación en todos sus niveles incluyendo el acceso a becas así como el ejercicio de las libertades de asociación, sindicación y reunión con limitaciones.

${ }^{11}$ El artículo 6 de la LO 8/2009, de 11 de diciembre, sobre "Participación pública», señala: 1. Los extranjeros residentes en España podrán ser titulares del derecho de sufragio, en las elecciones municipales, en los términos establecidos en la Constitución, en los tratados internacionales, en su caso, y en la Ley. 2. Los extranjeros residentes, empadronados en un municipio, tienen todos los derechos establecidos por tal concepto en la legislación de bases de régimen local, pudiendo ser oídos en los asuntos que les afecten de acuerdo con lo que disponga la normativa de aplicación. 3. Los Ayuntamien- 
con ocasión del Tratado de Maastricht y con el fin de que pudieran votar los ciudadanos comunitarios en comicios locales, se reformó el artículo 13.2 CE.

A efectos académicos Torres del Moral propone la catalogación de los derechos y de las libertades reconocidos en la CE en cuatro grupos: derechos civiles individuales, libertades públicas, derechos políticos y derechos de prestación como "categorías no siempre excluyentes entre sí». Como "presupuestos para el disfrute y ejercicio de los derechos» (o de ciertos derechos) señala la vida, la nacionalidad y la mayoría de edad. En el grupo de «libertades públicas» incluye las «libertades de reunión y manifestación» indicando que "ambas tienen una vertiente acusada y específicamente política»; la «libertad de asociación» en sus vertientes "general, profesional, sindical y política», señalando que ésta última «presenta una indudable faceta de derecho político, sobre todo para el ejercicio del derecho de sufragio pasivo»; el «derecho a dirigirse a las autoridades públicas o derecho de petición»; el «derecho de fundación»; el «derecho de negociación laboral colectiva» indicando que "puede ser considerado también derecho social» y el «derecho a adoptar medidas de conflicto colectivo, incluida la huelga». En el grupo de «derechos políticos» agrupa el de participación incluyendo el derecho de sufragio activo (en elecciones y referendos); derecho de sufragio pasivo; derecho de iniciativa legislativa popular, derecho de acceso a las funciones y cargos públicos; derecho al desempeño de dichos cargos en condiciones de igualdad y sin restricciones indebidas; la libertad de ideología política; la libertad de asociación política y las libertades de reunión y manifestación políticas. Subraya que los tres últimos ítems ya han sido citados en otros grupos de clasificación.

La CE consigna en su artículo 13.1 que «los extranjeros gozarán en España de las libertades públicas que garantiza el presente título (el Título I) en los términos que establezcan los tratados y la ley». El Tribunal Constitucional (TC) afirma que esa expresión de libertades públicas no tiene aquí un significado técnico y restrictivo, sino amplio, equivalente a derechos y libertades. Asumido así, la igualdad o desigualdad en la titularidad de derechos y libertades dependerá de lo que en cada caso dispongan la Constitución, los tratados y las leyes. (STC 107/1984, de 23 de noviembre). Advierte Torres del Moral: «No queda totalmente desconstitucionalizado el estatuto jurídico del ex-

tos incorporarán al padrón a los extranjeros que tengan su domicilio habitual en el municipio y mantendrán actualizada la información relativa a los mismos. 4. Los poderes públicos facilitarán el ejercicio del derecho de sufragio de los extranjeros en los procesos electorales democráticos del país de origen. 
tranjero pues sus derechos no pueden ser otros distintos de los que garantiza el título I de la Constitución. Pero su configuración ha de hacerse por ley y por tratados, que pueden establecer condiciones de titularidad y de ejercicio distintos a los nacionales. En este punto la doctrina y la jurisprudencia suelen diferenciar tres clases de derechos: a) aquellos cuyos sujetos son todas las personas; b) los que no corresponden en ningún caso a los extranjeros y c) aquellos que pueden corresponderles o no, dependiendo ello (más el modo, los límites y los procedimientos de su ejercicio) de las leyes y los tratados que los regulan». En este marco Torres del Moral establece esta división: a) Los derechos de la personalidad o de la dignidad humana, sobre los que existe igualdad; es lo que sucede con los derechos a la integridad física y psíquica, a la intimidad personal y familiar, a la libertad ideológica, etc., que, sin necesidad de tratado ni de ley, la propia Constitución reconoce a todos y no sólo a los españoles; b) Los derechos de participación política, salvo en el nivel local, se entienden como exclusivamente nacionales y, por tanto, no pertenecen en modo alguno a los extranjeros. Este es el grupo de derechos políticos objeto de este artículo, concretamente el derecho al sufragio en elecciones locales ejercido por ciudadanos latinoamericanos tras la suscripción de convenios de reciprocidad y c) El tercer grupo, el más polémico, es el de aquellos derechos que pueden estar o no reconocidos a los extranjeros y en los que los tratados y las leyes europeas varían. Son, en general, las libertades públicas, con excepciones, y algunos derechos sociales. derechos de reunión, manifestación, asociación, asociación sindical, huelga, etc. (STC 99/1985, de 30 de septiembre).

En lo que a los extranjeros se refiere, los autores de «Los derechos de participación como elemento de participación de los inmigrantes ${ }^{12}$ señalan que hay dos tipos de criterios para catalogar la participación de los inmigrantes. «Participación hace referencia a la participación política mediante el derecho de sufragio y/o la actividad de los partidos políticos, y a la participación cívica, entendida como la implicación en la vida asociativa y en los mecanismos y canales institucionales de participación». El Foro para la Integración Social de los Inmigrantes considera que los derechos correspondientes a este grupo están catalogados como elementos de «participación política indirecta» o "participación ciudadana o cívica» calificados como el

12 De Lucas, Martín; Añón, María José; Saura, Ángeles; Añón, José; Mestre, Ruth; Miravet, Pablo, Ruiz, Mario; Noguera, Carles; Solanes, Ángeles y TORRES, FRANCISCO, Los derechos de participación como elemento de integración de los inmigrantes, Madrid, Informes 2008 Economía y Sociedad Fundación BBVA, pág. 105. 
«resto de derechos políticos», a saber: derechos de reunión, asociación y manifestación ${ }^{13}$.

En este contexto el profesor David Moya Malapeira ${ }^{14}$ señala que «respecto de los derechos de participación distintos al sufragio cabe señalar que ha sido su conexión con los derechos civiles, laborales y sociales lo que ha facilitado su progresiva extensión a los extranjeros». Tal extensión, añade, "ha acabado arrastrando en la segunda mitad del siglo XX a derechos como los de asociación, reunión, manifestación, sindicación o huelga».

\section{MARCO LEGAL CORRESPONDIENTE A LOS RESIDENTES LATINOAMERICANOS EN ESPAÑA}

La legislación española en este terreno se encuentra en proceso de ampliación de forma cualitativa y cuantitativa a nivel nacional e internacional. Así, la tendencia es la de ampliar el reconocimiento de la titularidad y el ejercicio de derechos civiles y políticos a favor de los extranjeros residentes y, concretamente, de los latinoamericanos.

\section{La Constitución Española y los tratados internacionales}

Según el artículo 10.2 CE, «las normas relativas a los derechos fundamentales y a las libertades que la Constitución reconoce se interpretarán de conformidad con la Declaración Universal de los Derechos Humanos ${ }^{15}$ y los tratados y acuerdos internacionales sobre las

${ }^{13}$ FORO PARA LA INTEGRACIÓN SOCIAL DE LOS INMIGRANTES, La participación politica de las personas inmigrantes. Madrid, 2011. pág. 26.

${ }^{14}$ Moya MalaPeIRA, David, y ViÑAs Ferrer, AlBA, Sufragio y participación politica de los extranjeros extracomunitarios en Europa, Barcelona, Fundación Carles Pi i Sunyer, 2010.

${ }^{15}$ Estos son los artículos que resultan pertinentes de la DUDH: Artículo 1: Todos los seres humanos nacen libres e iguales en dignidad y derechos. Artículo 2: Toda persona tiene los derechos y libertades proclamados en esta declaración, sin distinción alguna de raza, color, sexo, idioma, religión, opinión política o de cualquier otra índole, origen nacional o social, posición económica, nacimiento o cualquier otra condición. Además no se hará distinción alguna fundada en la condición política, jurídica o internacional del país o territorio de cuya jurisdicción dependa una persona. Artículo 7: Todos son iguales ante la ley y tienen, sin distinción alguna, derecho a igual protección de la ley. Todos tienen igual protección contra toda discriminación que infrinja esta Declaración y contra toda provocación a tal discriminación». Artículo 23.4: Toda persona tiene derecho a fundar sindicatos y a sindicarse para la defensa de sus intereses. No obstante, tal como señala ALEMAÑY, Rosario, "¿También los 
mismas materias ratificados por España». El régimen jurídico de los derechos de los extranjeros en la CE se centran en el artículo $13 \mathrm{CE}$, tal como señala Rosario Mora Alemañy ${ }^{16}$.

El Pacto Internacional de Derechos Civiles y Políticos, de 19 de diciembre de 1966, señala que los derechos que recoge deben ser reconocidos a todas las personas sin distinción de «raza, color, sexo idioma, religión, opinión política o de otra índole, origen nacional o social, posición económica, nacimiento o cualquier otra condición social» (artículo 2) subrayando la igualdad ante la ley de cara a la protección de todas las personas sin discriminación (artículo 26). Por su parte el Convenio Europeo para la Protección de los Derechos Humanos y de las Libertades Fundamentales, de 4 de noviembre de 1950, indica que «el goce de los derechos y libertades reconocidos en el presente Convenio ha de ser asegurado sin distinción alguna, especialmente por razones de sexo, raza, color, lengua, religión, opiniones políticas u otras, origen nacional o social, pertenencia a una minoría nacional, fortuna, nacimiento o cualquier otra situación».

En este marco Rosario Mora Alemañy ${ }^{17}$ recuerda la conocida clasificación tripartita de los derechos fundamentales de los extranjeros según el TC mediante la STC 107/1984: los que pertenecen por igual a españoles y extranjeros; los que no pertenecen en modo alguno a los extranjeros, y aquellos otros «que pertenecerán o no a los extranjeros según dispongan los tratados y las leyes», tal como apunta Torres del Moral. Y añade: «Es en este último grupo donde resulta admisible la inclusión del dato de la nacionalidad para modular el ejercicio del derecho, introduciendo la diferencia de trato con los españoles», señala Mora Alemañy. La autora subraya que «el problema surge a la hora de determinar qué derechos pertenecen a los extranjeros en igualdad con los españoles y cuáles les pertenecen en los términos

extranjeros son iguales ante la ley?». Revista de Derecho de la UNED, núm. 12, 2013, págs. 568, 569, citando a M. ${ }^{a}$ DEL CARMEN VIDAL FuEYo en Constitución y extranjería, Madrid, CEPC, 2002, sólo dos derechos reconocidos en la DUDH están reconocidos exclusivamente reconocidos a favor de los respectivos nacionales de los Estados, tal como señala el artículo 21: 1. Toda persona tiene derecho a participar en el gobierno de su país, directamente o por medio de representantes libremente escogidos. 2. Toda persona tiene el derecho de acceso, en condiciones de igualdad, a las funciones públicas de su país. 3. La voluntad del pueblo es la base de la autoridad del poder público; esta voluntad se expresará mediante elecciones auténticas que habrán de celebrarse periódicamente, por sufragio universal e igual y por voto secreto u otro procedimiento equivalente que garantice la libertad del voto.

${ }^{16}$ Mora AlEmañy, Rosario, "¿También los extranjeros son iguales ante la ley?». Revista de Derecho de la UNED, núm. 12, 2013, págs. 568, 569.

${ }^{17}$ Mora Alemañy, cit. en n. ${ }^{\circ}$ 16, pág. 576. 
que establezcan los tratados o la ley... El frecuente recurso del TC al lábil criterio del grado de vinculación del derecho con la dignidad humana para determinar su pertenencia a uno u otro grupo de derechos no ofrece suficiente claridad y certeza...». Y concluye que "es necesario que el TC fije con mayor precisión las directrices a seguir en esta materia».

En la STC 236/2007 el TC reconoce a los extranjeros los derechos de reunión, manifestación, asociación, sindicación y huelga, educación no obligatoria y justicia gratuita en las mismas condiciones que a los españoles pero separando entre titularidad y ejercicio de los derechos de modo que la titularidad se reconoce para todos los extranjeros, al margen de su situación administrativa, es decir, al margen de si tienen o no papeles de residencia legal en España, pero su ejercicio se reserva para aquellos que cuentan con tal residencia legal. La STC 236/2007 señala que el requisito de residencial legal es inconstitucional respecto de los derechos de tutela judicial efectiva, a la educación y a la huelga (este último según la STC 259/2007). Sí es requisito el de la residencia legal para el ejercicio de los derechos de reunión y manifestación, asociación y libertad sindical.

Pertinente es asimismo en este marco el artículo 6.1 del Convenio del Consejo de Europa sobre la participación de los extranjeros en la vida pública a nivel local, firmado el 5 de febrero de 1992, que señala que "cada Estado parte se compromete, a reserva de las disposiciones del artículo 9.1, a conceder el derecho de voto activo y pasivo en las elecciones locales a todo extranjero residente, con tal de que este cumpla las mismas condiciones que se aplican a los ciudadanos y, además, haya residido legal y habitualmente en el Estado en cuestión durante los cinco años anteriores a las elecciones ${ }^{18}$.

Asimismo en la legislación nacional tenemos que terminan de configurar de forma sustancial la base del derecho de sufragio de los extranjeros en España el ya comentado artículo 6 de la LO 4/2000 (artículo 6) ${ }^{19}$ y los artículos 176 y 177 la Ley Orgánica 5/1985, de 19 de

${ }^{18}$ Este artículo sería la base de que en los tratados de reciprocidad en materia de sufragio en elecciones locales firmados por España desde 2009 se exija a quienes se acojan a ellos un periodo mínimo de residencia legal en España de cinco años. Cuestión distinta es la diferenciación que se hace en estos tratados respecto de lo que sucede con los nacionales de la Unión Europea ya que los tratados con países no comunitarios contemplan el derecho al voto activo más no al voto pasivo.

${ }^{19}$ Ver n. ${ }^{\circ} 11$. 
julio, de Régimen Electoral General (LOREG) ${ }^{20}$. En lo que respecta a los inmigrantes latinoamericanos, concretamente, los tratados internacionales de mayor relevancia son los de Doble Nacionalidad cuya aplicación está delimitada por el Código Civil ${ }^{21}$.

\section{Tratados de reciprocidad en materia de sufragio en elecciones locales suscritos con países latinoamericanos}

Desde el año 2000 diversas iniciativas parlamentarias abordaron el reconocimiento del derecho de sufragio a los extranjeros residentes en España. Si bien dichas iniciativas se refieren en general al conjunto de inmigrantes residentes, sin distinción de nacionalidad, la mayor parte hace referencia a la especial vinculación española con los países latinoamericanos ${ }^{22}$. No obstante, estas iniciativas no llegaron a plasmarse legislativamente.

${ }^{20}$ LOREG. Artículo 176: 1 . Sin perjuicio de lo regulado en el Título I, capítulo I, de esta Ley, gozan del derecho de sufragio activo en las elecciones municipales los residentes extranjeros en España cuyos respectivos países permitan el voto a los españoles en dichas elecciones, en los términos de un tratado. Asimismo, gozan del derecho de sufragio activo en las elecciones municipales todas las personas residentes en España que, sin haber adquirido la nacionalidad española: a) Tengan la condición de ciudadanos de la Unión Europea según lo previsto en el párrafo 2 del apartado 1 del artículo 8 del Tratado Constitutivo de la Comunidad Europea. b) Reúnan los requisitos para ser elector exigidos en esta Ley para los españoles y hayan manifestado su voluntad de ejercer el derecho de sufragio activo en España. 2. El Gobierno comunicará a la Oficina del Censo Electoral la relación de Estados extranjeros cuyos nacionales, residentes en España, deban de ser inscritos en el censo. Artículo 177: 1. Sin perjuicio de lo dispuesto en el capítulo II del Título I de esta Ley, son elegibles en las elecciones municipales todas las personas residentes en España que, sin haber adquirido la nacionalidad española: a) Tengan la condición de ciudadanos de la Unión Europea según lo previsto en el párrafo 2 del apartado 1 del artículo 8 del Tratado Constitutivo de la Comunidad Europea, o bien, sean nacionales de países que otorguen a los ciudadanos españoles el derecho de sufragio pasivo en sus elecciones municipales en los términos de un tratado. b) Reúnan los requisitos para ser elegibles exigidos en esta Ley para los españoles. c) No hayan sido desposeídos del derecho de sufragio pasivo en su Estado de origen. 2. Son inelegibles para el cargo de Alcalde o Concejal quienes incurran en alguno de los supuestos previstos en el artículo 6 de esta Ley y, además, los deudores directos o subsidiarios de la correspondiente Corporación Local contra quienes se hubiera expedido mandamiento de apremio por resolución judicial.

${ }^{21}$ Ver n. $^{\circ} 2$ y n. ${ }^{\circ} 3$.

${ }^{22}$ La Proposición No de Ley de los Grupos Parlamentarios Socialista e Izquierda Unida Iniciativa per Cantalunya Verds de 10 de julio de 2006, publicada en el Boletín Oficial de las Cortes Generales el 11 de septiembre de 2006, sobre la extensión del derecho a voto, en las elecciones municipales, a los extranjeros residentes legales, para su debate en el Pleno de la Cámara, indica que «es necesario que el Gobierno proceda a negociar acuerdos con países que tengan un mayor número de nacionales viviendo legalmente en nuestro país y, en especial, con aquellos, como los países lati- 
Tras diversas manifestaciones de buenas intenciones, en 2009 por fin se plasmó en hechos la voluntad política mayoritaria de las Cortes que, hasta la fecha, ha permitido la firma de quince acuerdos de reciprocidad en materia de sufragio en elecciones locales, instrumentados mediante canjes de notas. Entre los acuerdos firmados con países latinoamericanos han sido ratificados y han entrado en vigor los suscritos con Bolivia, Chile, Colombia, Ecuador, Paraguay y Perú. Estos convenios permitieron que los ciudadanos de dichos países residentes en España pudieran votar en las elecciones locales celebradas el 22 de mayo de 2011. También se han suscrito convenios de reciprocidad en materia de sufragio en elecciones locales con otros tres países latinoamericanos, Argentina, Uruguay y Venezuela, convenios cuyas ratificaciones y entrada en vigor están pendientes. Igualmente el Gobierno Español ha ofrecido la firma de acuerdos para el reconocimiento del derecho al voto de sus nacionales en elecciones locales, en condiciones de reciprocidad, si cambian su legislación para que tal reciprocidad sea efectiva, a ocho países latinoamericanos: Costa Rica, República Dominicana, El Salvador, Guatemala, Honduras, México, Nicaragua y Panamá. Los acuerdos con países latinoamericanos firmados y que pueden ser negociados son mayoría por voluntad del legislador emanada de los especiales vínculos históricos y culturales hispano-latinoamericanos.

A nivel jurídico es preciso señalar que los acuerdos de Cooperación y Amistad suscritos por España con Argentina, Colombia, Uruguay, Venezuela y Chile contemplan la concesión recíproca a los nacionales de los Estados firmantes del derecho de voto en las elecciones municipales del Estado en el que residen aunque no sean sus nacionales. Estos tratados están sujetos a la realización de acuerdos complementarios posteriores que no han llegado a materializarse. Este último requisito no se expresa en el tratado correspondiente con Chile lo que, para algunos autores, significa que los chilenos tenían

noamericanos, con los que tenemos mayores vínculos históricos, culturales y afectivos». E insta al Gobierno a: 1) Proceder a la negociación y firma de acuerdos o convenio con los países con mayor número de nacionales residentes legales en España y, especialmente, con aquellos con los que ésta tiene relaciones históricas, políticas y culturales más estrechas, al objeto de que dichos nacionales puedan votar y ser elegidos en las elecciones municipales en España con arreglo al artículo 13.2 de la Constitución. 2) Solicitar del Consejo de Estado un informe sobre la aplicación del artículo 13.2 de la Constitución a los efectos de la participación de los extranjeros residentes en España en las elecciones municipales, y, particularmente, sobre la interpretación de los términos "criterios de reciprocidad» a que se refiere el precepto citado». 3) La firma y ratificación del Convenio Europeo sobre Participación de los Extranjeros en la Vida Pública Local, de 5 de febrero de 1.992. 
reconocido el derecho de sufragio en elecciones locales en España desde la firma del citado convenio ${ }^{23}$.

Los tratados mencionados, además de la reciprocidad exigida por la $\mathrm{CE}^{24}$, incluyen requisitos que diversas asociaciones de inmigrantes han criticado ya que, en la práctica, restringen en gran medida el número de personas que pueden acogerse a ellos. El primero de estos requisitos es el de residir al menos durante cinco años de forma legal e ininterrumpida en España ${ }^{25}$ lo que, en el caso de los ciudadanos latinoamericanos, en cierto modo desvirtúa la existencia misma de estos tratados pues, tal como señala el Código Civil, para solicitar acogerse a los correspondientes tratados de Doble Nacionalidad solo se requieren dos años de residencia legal e ininterrumpida y, en algunos casos, apenas se requiere de un año de residencia ${ }^{26}$. La segunda restricción es que dichos tratados limitan el reconocimiento y el ejercicio del derecho al voto activo ${ }^{27}$. Si bien gran parte de los analistas de la

${ }^{23}$ CARrasco Durán, Manuel. «El derecho de voto de los extranjeros en las elecciones municipales. Nuevas realidades». QDL, Fundación Democracia y Gobierno Local, n. 22, 2010, págs. 151 y 152. Artículo 9 del Tratado general de cooperación y amistad con la República Argentina de 9 de junio de 1989 (BOE de 28 de agosto de 1989), artículo 11 del Acuerdo general de cooperación y amistad con Venezuela de 7 de junio de 1990 (BOE de 16 de julio de 1992), artículo 17 del Tratado general de cooperación y amistad con Chile de 19 de octubre de 1990 (BOE de 22 de agosto de 1991), artículo 15 del Tratado general de cooperación y amistad firmado con la República Oriental de Uruguay de 23 de julio de 1992 (BOE de 2 de junio de 1994), y artículo 13 del Tratado general de cooperación y amistad con la República de Colombia, de 29 de octubre de 1992 (BOE de 1 de agosto de 1995).

${ }^{24}$ Hay autores que defienden la supresión del principio de reciprocidad. VACAS FERNÁNDEZ, Félix, «El principio de reciprocidad como condición del reconocimiento del derecho al sufragio de extranjeros en las elecciones municipales en España y sus implicaciones desde el Derecho Internacional». Revista de Derecho Migratorio y Extranjería. n. 20, 2009, pág. 77. El autor apunta al respecto que «la única solución jurídica posible» es "la supresión del principio de reciprocidad del artículo 13.2 CE».

${ }^{25}$ Cebrián, Juan AnTonio. «Extranjería y derecho de sufragio». Documento de la Fundación Ciudadanía y Valores, n. 108, 2011. pág. 6. El autor apunta que el requisito de cinco años de residencia legal e ininterrumpida en España se fundamenta en el Convenio del Consejo de Europa sobre participación de extranjeros en la vida pública en el ámbito local. "No obstante», añade, «se contempla la posibilidad de que cualquier Estado parte establezca unilateralmente, o mediante acuerdo bilateral o multilateral, un período de residencia menor de cinco años, como ocurre en el caso de los países pertenecientes a la «British Commonwealth of Nations», o en el de los países de habla portuguesa».

${ }^{26}$ Ver . $^{\circ} 3$.

${ }^{27}$ La reforma del artículo 13.2 de la CE, aprobada el 27 de agosto de 1992, para adaptarlo al Tratado de la UE. Según apunta Manuel Carrasco Durán, cit. en n.25, p. 156 , nada impide que también se reconozca a los nacionales de otros estados el derecho de sufragio pasivo. 
materia consideran que el derecho al voto pasivo debería extenderse, no hay unanimidad al respecto ${ }^{28}$.

Estas exigencias reducen el número de «los potenciales beneficiarios de los acuerdos a un número menor del que una primera aproximación pudiera hacer pensar» en palabras de Manuel Carrasco Durán ${ }^{29}$. El número de beneficiarios, asimismo, fue mucho menor de lo previsto en las elecciones de mayo de 2011 en virtud de una burocratizada y contradictoria normativa en torno al Censo Electoral de Residentes Extranjeros, CERE, como queda evidenciado en el siguiente capítulo del presente artículo ${ }^{30}$.

Asimismo no falta la corriente que considera que el Ordenamiento Jurídico podría contemplar reconocer a los extranjeros el derecho al voto en elecciones generales. Juristas expertos en la materia se inclinan a favor del hecho de que el derecho de sufragio en elecciones generales es exclusivo de los nacionales de cada país no obstante los ejemplos de países que admiten que los extranjeros voten en todo tipo de elecciones como sucede en Chile ${ }^{31}$. En esta corriente se sitúa el Observatorio Permanente de la Inmigración en Navarra ${ }^{32}$.

${ }^{28}$ Cebrián, JuAn Antonio. «Extranjería y derecho de sufragio». Revista de la Fundación Ciudadanía y Valores. Septiembre de 2011. pág. 6. El autor considera: «El reconocimiento limitado al derecho de sufragio pasivo es más coherente con un sistema jurídico como el español que, incluso para los Estados miembros de la UE, limita el acceso a la función pública».

${ }^{29}$ «El derecho de voto de los extranjeros en las elecciones municipales. Nuevas Realidades», QDL Fundación Democracia y Gobierno Local de 22 de febrero de 2010 , p. 161.

${ }^{30}$ El BOE del 5 de noviembre de 2012 publicó el procedimiento y la aprobación del modelo de solicitud para la inscripción en el cenco electoral de residentes en España de nacionales de países con acuerdos para las elecciones municipales: http:// www.boe.es/boe/dias/2010/11/05/pdfs/BOE-A-2010-17018.pdf

${ }^{31}$ Los extranjeros pueden votar en elecciones generales en Chile si cuentan con visado de residencia permanente y llevan viviendo en el país al menos cinco años: http://www.eleccionesenchile.com/informacion-pueden-votar-extranjeros-en-chile-117.html

${ }^{32}$ En «El derecho al voto de las personas extracomunitarias», del BOLETÍN DEL OBSERVATORIO PERMANENTE DE LA INMIGRACIÓN EN NAVARRA ENFOQUES, n. 14,2011 , p. 6 , se señala lo que se considera como «una contradicción que ocurre en las elecciones generales» haciendo notar que los extranjeros no comunitarios no pueden votar en tales comicios «a pesar de que desempeñan un rol relevante en la adjudicación de escaños por circunscripciones. La distribución de los 350 escaños del Congreso de Diputados se realiza en base a la población existente en cada circunscripción provincial y por ello los incrementos o disminuciones de población afectan al reparto. Por esto motivo incluso se da la paradoja de que inmigrantes inscritos en el padrón pero en situación administrativa irregular cuentan para este cálculo». 


\section{LOS LATINOAMERICANOS Y LAS ELECCIONES EN ESPAÑA}

Con el objetivo de sondear la eficacia de la legislación sobre el reconocimiento de la titularidad y el ejercicio de derechos civiles y políticos y la importancia que a ella le otorgan los ciudadanos latinoamericanos residentes en España se ha realizado la encuesta que se comenta en esta sección ${ }^{33}$ que compara la legislación aplicable con lo ocurrido en la práctica en las elecciones locales celebradas en España el 22 de mayo de 2011.

\section{Percepción de los derechos civiles y políticos y comportamiento electoral por parte de los inmigrantes latinoamericanos frente a otro tipo de derechos. Opinión sobre la actitud de la Administración $^{34}$}

Apoyándonos en los datos de la encuesta realizada tenemos que los latinoamericanos en España no perciben que los derechos civiles y políticos tengan especial relevancia en su proceso de integración. Entre doce temas prioritarios la falta de derechos civiles y políticos se encuentra en un noveno lugar mencionado como el principal obstáculo por apenas un $0,5 \%$ de encuestados. Por encima se encuentran el desempleo, la obtención de papeles de residencia y estancia legal en el país, la situación económica de España, la integración en la sociedad, la igualdad de oportunidades, el racismo, el rechazo y la integración de los hijos. No existe una especial sensibilidad hacia el tema porque en realidad no figura entre las prioridades de los extranjeros

${ }^{33}$ Ficha técnica de la encuesta. Universo: inmigrantes latinoamericanos en España (2.455.000 según la revisión del Padrón de 2011). Método de recogida de la información: entrevistas personales asistidas por ordenador (CAPI) mediante la administración de un cuestionario estructurado. La selección del entrevistado se ha efectuado en espacios púbicos siguiendo criterios de dispersión estándar. Tamaño y distribución de la muestra: 400 entrevistas. Se han aplicado cuotas de país de origen, sexo y edad de acuerdo a la estructura del Padrón. Ámbito: Comunidades Autónomas de Madrid, Andalucía, Valencia y Cataluña. Se han utilizado 34 puntos de muestreo. Error de muestreo: partiendo de los criterios del muestreo aleatorio simple y para un nivel de confianza del $95.5 \%$ (dos sigmas) y en la hipótesis más desfavorable $(p=q=50)$, el margen de error para los datos en el total de la muestra es del $\pm 5,0 \%$. Equipo de trabajo de campo: Equipo de entrevistadores de Instituto DYM. Proceso de datos: Departamento de Proceso de Datos de Instituto DYM. Fechas de trabajo de campo: 13-25 de marzo de 2012.

${ }^{34}$ El «Plan Estratégico de Ciudadanía e Integración 2011-2014», PECI II, de la Dirección General de Integración de los Inmigrantes, Madrid, septiembre de 2011, señala como el primero de sus diez objetivos establecer medidas que garanticen el pleno ejercicio de los derechos civiles, sociales, económicos, culturales y políticos de los inmigrantes. 
al menos en sus primeros años de experiencia migratoria centradas, básicamente, en su integración socioeconómica. Naturalmente la función del derecho es añadir una nueva vía de integración y que ésta sea asumida como tal en el imaginario colectivo de los extranjeros y de la sociedad en su conjunto.

Considerando que mientras más años se llevan viviendo en España es mayor el porcentaje de latinoamericanos que acceden al disfrute de derechos civiles y políticos (con dos años de residencia legal e ininterrumpida la mayoría puede iniciar el trámite para acogerse a los correspondientes convenios de Doble Nacionalidad ${ }^{35}$ ) se puede inferir que el goce de estos derechos es uno de los elementos que permiten que los inmigrantes se sientan más integrados en la sociedad.

Entre los motivos para sentirse integrados los encuestados valoran muy marginalmente el disfrute de derechos civiles y políticos, un tema que ocupa el décimo lugar entre once apartados, valorado por apenas el 1,3\% de los encuestados y que solo se encuentra por encima de la recepción de ayudas, valorado por el 1\%. Los motivos fundamentales para sentirse integrados citados por los encuestados son la adaptación, la vida social, el trato recibido, la cultura y las costumbres, el tiempo de permanencia en España, el arraigo, el trabajo, el idioma y las condiciones de vida. Así, pues, en la jerarquía de motivos para sentirse integrado ocupan los primeros lugares los factores relacionados con la vida cotidiana mientras que los factores relativos al sistema sociopolítico tienen una relevancia escasa.

El 40\% de los encuestados no echa en falta ningún derecho. En cualquier caso el derecho concreto más demandado es el del acceso a la función pública. En una escala decimal, entre los encuestados los derechos políticos obtienen 7,8 puntos de calificación. Los derechos económicos y sociales logran una puntuación de 9,1. En el marco concreto del ejercicio del voto, lo que más se puntúa es el derecho al voto en elecciones en general. En menor medida se valora la importancia de poder presentar una candidatura propia, aspecto que se califica con un $7,3 \%$.

En este marco la encuesta indica que, por edades, la falta de derechos civiles y políticos preocupa más a los mayores de 35 años. Sólo el 1,5\% de los encuestados con edades comprendidas entre los 18 y los 34 años lo considera un tema relevante. Por año de llegada a España es un tema que es citado como prioritario sobre todo por quienes llegaron entre 2001 y 2005 , el $4 \%$ de este grupo. Solo el 1,9\% de

${ }^{35}$ Ver n. 3. 
los encuestados que llegaron en el año 2000 o antes valora este tema como algo prioritario. Es menor la proporción de encuestados que lo cita entre quienes llegaron después de 2005 ya que solo el 1,4\% de este grupo lo considera. Por nacionalidades, los ciudadanos dominicanos son quienes en mayor proporción estiman que la falta de derechos civiles y políticos es un problema destacable. El 9,1\% de dominicanos encuestados lo considera. En segundo lugar se sitúan los ciudadanos argentinos; el 4,3\% de encuestados de esta nacionalidad mencionó el tema como prioritario. En tercer lugar el tema fue destacado por los ciudadanos venezolanos; de este grupo fue indicado por el $4 \%$ de encuestados. Los ciudadanos ecuatorianos ocupan el quinto puesto en este sentido; el 2,5\% de encuestados subrayó el tema. En sexto lugar se sitúan los ciudadanos colombianos; el 1,7\% de entrevistados de este colectivo señaló como importante el problema de falta de derechos civiles y políticos.

En cuanto a la calificación otorgada al derecho al voto, se valora más el voto en elecciones municipales, con 8,05 puntos. El voto en elecciones autonómicas y nacionales se califica con 7,97 puntos. En este contexto por nacionalidades el voto en comicios municipales es calificado con 8,98 puntos por los argentinos; con 8,15 puntos por los colombianos; con 8,12 puntos por los bolivianos; con 8,08 puntos por los ecuatorianos; con 7,83 puntos por los brasileños; con 7,64 puntos por los dominicanos; con 7,6 puntos por los venezolanos y con 7,53 puntos por los peruanos. El voto en elecciones autonómicas y nacionales se puntúa con 8,89 puntos por los argentinos; con 8,13 puntos por los brasileños; con 8,03 puntos por los colombianos; con 7,99 puntos por los ecuatorianos; con 7,86 puntos por los dominicanos; con 7,73 puntos por los bolivianos; con 7,68 puntos por los venezolanos y con 7,56 puntos por los peruanos.

Los derechos políticos no se encuentran entre los más demandados por los inmigrantes latinoamericanos en España si bien el derecho al voto ocupa el tercer lugar en esta escala. El derecho al voto es echado en falta por el 8,3\% de los encuestados. El 4,5\% echa en falta los derechos políticos en general y el 2,5\% señala en este caso el derecho a ejercer el derecho al voto pasivo, es decir, a ser candidato en elecciones en España. El primer lugar es ocupado por el derecho al acceso a la función pública en igualdad de condiciones que los ciudadanos españoles. El 17,5\% de encuestados lo señala como el derecho que más echa en falta. En segundo lugar se sitúan los derechos económicos y sociales en general, que reclama un 15,5\% de los encuestados. Tras el derecho al voto, en cuarto lugar se ubica el derecho a la igualdad, citado como ausente por un 5,3\% de los encuestados, a pe- 
sar de que es un derecho consagrado como fundamental por el Título I CE incluyendo a los extranjeros con la salvedad del derecho al voto y del derecho al acceso a la función pública. La falta de papeles es citada en séptimo lugar, mencionada por un $4 \%$ de los encuestados. Tras el derecho a ser candidato político, los siguientes derechos echados en falta por los encuestados son el de residencia (1\%), el de nacionalidad (1\%), el de libertad de expresión $(0,5 \%)$-no obstante que también es un derecho fundamental según la $\mathrm{CE}$, con sus correspondientes límites- y el de convalidación de estudios $(0,3 \%)$. Como dato resaltante en este contexto cabe mencionar que el 35,5\% de encuestados no echa en falta ningún derecho y que el $8,5 \%$ no supo o no quiso contestar a la pregunta.

Para poder valorar si esta actitud distante sobre los derechos civiles y políticos y sobre el derecho al voto en particular es un comportamiento que el colectivo analizado ya desarrollaba en sus países de origen, la encuesta consultó sobre el ejercicio de sufragio en elecciones en los países de los que proceden los latinoamericanos residentes en España. Y tenemos que el ejercicio del derecho al voto es muy escaso en el colectivo en cuestión en este marco. Solo el 17\% de los encuestados vota desde España en las elecciones que se celebran en su país de origen. El 22\% de los que no cuentan con nacionalidad española declaran haberse inscrito en el censo electoral para ejercer en España el derecho al voto en elecciones locales conforme permiten los correspondientes convenios de reciprocidad suscritos por sus países de origen con España. Y apenas el 9\% señala haber votado en alguna de las elecciones celebradas en España ${ }^{36}$.

No obstante el 58,5\% de los encuestados manifiesta que votaba «siempre o casi siempre» cuando residía en sus país de origen. El $16,3 \%$ dice que lo hacía "algunas veces» y el 25,3\% señala que no lo hizo nunca o lo hizo «casi nunca». La tendencia, como parece lógico, se invierte a la hora de ejercer el derecho al voto en elecciones en el país de origen votando desde España. Así, el 71,3\% de los encuestados indica que lo hace "nunca o casi nunca», el 17\% que lo hace «siempre o casi siempre» y el 11,8\% que sólo lo hace «algunas ve-

${ }^{36}$ La participación política suele ser mayoritaria entre los ciudadanos nacionales de origen. AinhoA URIBE, en «V Simposio Internacional de Inmigración. Derechos humanos e inmigración: inmigración y participación política», en Documentos de la Fundación Ciudadanía y Valores, 2011, pág. 21, señala: «se vislumbra que los nacionales participan más que los foráneos (sean estos comunitarios o extracomunitarios). Las razones que reposan en esta menor tasa de participación política pueden ser muy diversas y obedecen a la cultura política de los extranjeros y a los mecanismos a través de los cuales estas personas adquieren valores, actitudes y conocimientos sobre el sistema político, esto es, a su socialización política». 
ces». Estos datos corroboran que entre las prioridades de los inmigrantes en sus primeras etapas de arraigo no se encuentra la participación política.

Igualmente en torno al voto en elecciones políticas en España, entre los encuestados sin nacionalidad española predominan claramente quienes nunca han ejercido tal derecho: el 92,1\%. En este grupo solo el 5,3\% de encuestados manifiesta haber votado en las elecciones locales del 22 de mayo de 2011. Entre los encuestados que también cuentan con nacionalidad española la proporción es inversa. En este grupo el 68,4\% de encuestados manifiesta que sí ha votado en elecciones en España. El 58,2\% de encuestados pertenecientes a este grupo indica que votó en las elecciones locales del 22 de mayo de 2011. En resumen, el ejercicio del voto en elecciones en España es muy escaso entre los inmigrantes latinoamericanos que no cuentan con nacionalidad española. Entre quienes sí tienen nacionalidad española el ejercicio del derecho al voto está en línea con el resto de los ciudadanos españoles.

En el marco de las últimas elecciones generales, celebradas en España el 20 de noviembre de 2011, -a las que, como es lógico, solo estaban convocados aquellos ciudadanos latinoamericanos que también tienen nacionalidad española- entre los motivos señalados para acudir a votar se señala en primer lugar el hecho de poseer el derecho al voto $(35,1 \%)$, el interés general $(24,6 \%)$, el deseo de participar $(21,1 \%)$, el deseo de apoyar a un partido político concreto $(12,3 \%)$ y el hecho de vivir en España (3,5\%).

En cuanto a si la Administración Pública Española es proclive a facilitar el reconocimiento y el ejercicio de estos derechos a los inmigrantes, el 40,3\% de encuestados respondió considerando que sí (mucho o bastante). El 31\% considera que la Administración Española es algo proclive a facilitar el reconocimiento y el ejercicio de estos derechos. Y el 28,8\% señaló que la Administración es poco o nada proclive en este sentido.

A la hora de responder sobre las facilidades que los gobiernos españoles otorgan a la integración son los dominicanos quienes encabezan la lista de quienes consideran que tales facilidades son muchas o bastantes. El 63,6\% de dominicanos encuestados es de esta opinión. Los peruanos siguen en la lista pues el 62,5\% de personas encuestadas de esta nacionalidad opina algo similar. Siguen los venezolanos $(60 \%)$, los colombianos $(58,3 \%)$, los bolivianos $(54,5 \%)$, los brasileños $(52,2 \%)$, los ecuatorianos $(48,1 \%)$ y los argentinos $(40,4 \%)$. Llama la atención, pues, que los argentinos sean quienes 
más integrados se sienten pero quienes en menor medida, entre las nacionalidades mayoritarias analizadas, consideran que los gobiernos facilitan tal integración. Esta circunstancia se debería a que gran parte de los argentinos residentes en España cuentan desde el inicio de su estancia con una nacionalidad habilitante para vivir de forma legal (generalmente la española o la italiana) y también para poder sufragar en comicios, al menos a nivel local, por lo que no valoran especialmente la intervención gubernamental específica para facilitar la integración.

Asimismo tenemos que el tratamiento legislativo español respecto de los latinoamericanos en España no es homogéneo dependiendo de las nacionalidades. Así, se puede deducir que la opinión favorable de los ciudadanos peruanos encuestados sobre las facilidades que dan los gobiernos en este marco se fundamentaría, entre otros puntos, en el hecho de que los peruanos cuentan con una ventaja comparativa respecto del resto de inmigrantes a la hora de lograr permiso de trabajo ya que no deben verificar primero en los servicios de empleo si hay desempleados españoles o residentes en el sector correspondiente y logran el permiso de residencia y trabajo si cumplen con el resto de requisitos. Esta ventaja también es disfrutada por los ciudadanos chilenos y en ambos casos deriva de la especificidad de los respectivos convenios de Doble Nacionalidad suscritos entre España y Perú y entre España y Chile ${ }^{37}$.

En cualquier caso la tendencia de la legislación española es la de ampliar el reconocimiento de la titularidad y del ejercicio del derecho al voto en comicios locales y la de subsanar los errores sucedidos ${ }^{38}$.

${ }^{37}$ Los ciudadanos de Perú y Chile son los únicos entre los extranjeros no comunitarios o pertenecientes a los países del Territorio Schengen que pueden vivir y trabajar en España al margen de la situación nacional de empleo, es decir, si cuentan con la correspondiente oferta laboral aunque haya españoles o residentes legales que se encuentran desempleados en los sectores objeto de las citadas ofertas laborales. Esta preferencia se sustenta en la especificidad de los convenios de Doble Nacionalidad suscritos por Espala con Perú y Chile (artículos 7 y 8) y que la legislación nacional aplica tal como lo indica el Ministerio de Empleo y Seguridad Social: http://extranjeros.empleo.gob.es/es/InformacionInteres/InformacionProcedimientos/Ciudadanosnocomunitarios/hoja096/

${ }^{38}$ Autores de diversas líneas destacan que de cara a las elecciones municipales de 2015 «el voto extranjero tendrá una importancia creciente y pasará a ser realmente influyente», como apunta Juan Antonio CEBRIÁN, cit. en n. 29. 


\section{Valoración de los partidos políticos. Partidos políticos formados por inmigrantes. Intención de voto}

En general se puede inferir que los partidos políticos españoles no son sentidos como cercanos por los inmigrantes latinoamericanos en España. Según la encuesta, siete de cada diez latinoamericanos en España no se sienten representados por ningún partido político español. Ante la pregunta del sentimiento de representatividad por algún partido político el 70,2\% de encuestados respondió con una negativa.

Resalta el hecho de que, de acuerdo al sondeo, un partido político formado por inmigrantes sí tendría un apoyo mayoritario por los encuestados, de seis de cada diez inmigrantes latinoamericanos. El $62,5 \%$ indicó que sí apoyaría a un partido político en España formado por inmigrantes. Se observa, pues, un destacable distanciamiento de las opciones políticas actuales. Este dato permite inferir que el voto pasivo podría ejercer influencia en la formación de candidaturas así como en los resultados electorales ${ }^{39}$.

Por nacionalidades, si bien en ningún caso se llega al 50\%, quienes en mayor medida se sienten representados por los partidos políticos actuales son los venezolanos (48\%). En segundo lugar se encuentran los bolivianos $(45,5 \%)$ seguidos por los peruanos $(43,8 \%)$, los dominicanos $(36,4 \%)$, los ecuatorianos $(29,1 \%)$, los colombianos $(26,7 \%)$, los argentinos $(23,4 \%)$ y los brasileños (13\%). Quienes menos se sienten representados en este sentido, pues, son los brasileños y los argentinos.

Sobre el derecho de los inmigrantes a presentar candidaturas (derecho al voto pasivo), el 71,8\% respondió que solo alguno de los inmigrantes tenía reconocido este derecho y el 21,5\% señaló que todos tenían reconocido el derecho, evidenciándose más aun la falta de información (solo de puede ejercer el derecho al voto activo). Solo el 6,8\% indicó que ningún inmigrante tenía derecho a presentar candidaturas.

Quienes, evidentemente, sí tienen derecho a ejercer el derecho al voto tanto pasivo como activo son aquellos inmigrantes que se han

${ }^{39}$ Las modalidades de ejercicio del sufragio activo y pasivo por los ciudadanos comunitarios fueron aclaradas a través de la Directiva del Consejo 94/80/CE, de 19 de diciembre de 1994. La normativa se desarrolla a través de la Directiva 96/30/CE, de 13 de mayo de 1996, que amplía el sufragio a los nacionales de Austria, Finlandia y Suecia; la Directiva de 23 de septiembre de 2003, para la República Checa, Estonia, Chipre, Lituania, Hungría, Malta, Polonia, Eslovenia y Eslovaquia; y la Directiva 2006/106/CE de 20 de noviembre de 2006, relativa a Bulgaria y Rumania. 
acogido a los correspondientes convenios de doble nacionalidad ${ }^{40}$. Ya ha habido casos de ciudadanos latinoamericanos que han presentado candidaturas en diversas elecciones en España gracias a su condición de españoles merced a los mencionados convenios. Sin embargo el $79,4 \%$ de encuestados señaló que no conocía a ningún candidato de origen extranjero en elecciones españolas. El 4,6\% indicó que sabía de casos de personas de origen extranjero que habían presentado candidaturas pero sin poder identificar sus nombres. Solo el 1,3\% precisó nombres de candidatos en elecciones españolas de origen extranje$\mathrm{ro}^{41}$.

En cuanto a las opciones políticas, las de centro izquierda aparecen en la cúspide de las preferencias de los latinoamericanos en España. Entre los partidos mayoritarios, la mitad de los encuestados prefiere al Partido Socialista Obrero Español (PSOE). Según los encuestados, el PSOE es el partido que más se preocupa por el bienestar de los inmigrantes latinoamericanos en el reconocimiento y el ejercicio de derechos económicos y sociales (55\%), el apoyo a la integración $(54,3 \%)$, la obtención de documentación $(54,3 \%)$, el reconocimiento y el ejercicio de derechos políticos $(49,5 \%)$, el empleo $(48,8 \%)$ y la economía en general (41,5\%). El Partido Popular (PP) es valorado por menos de un 10\% de los encuestados en cada uno de los aspectos señalados con excepción de su preocupación por la economía en general ya que el 12,8\% considera que este tema es prioritario para este partido. En los temas de reconocimiento y otorgamiento de facilidades para el ejercicio de los derechos políticos de los inmigrantes sólo el 6,5\% considera que esta es una preocupación del PP mientras que el 7,3\% opina que el PP se preocupa por que los inmigrantes gocen del reconocimiento y el ejercicio de derechos económicos y sociales.

${ }^{40}$ En la publicación "Concesiones de nacionalidad española por residencia», Secretaría Nacional de Inmigración e Inmigración, Ministerio de Empleo y Seguridad Social, Madrid, 25 de octubre de 2013, http://extranjeros.empleo.gob.es/es/Estadisticas/operaciones/concesiones/, se indica que solo entre 2002 y 2012 se concedió la nacionalidad española a 611,897 latinoamericanos, entre argentinos, bolivianos, brasileños, chilenos, colombianos, costarricenses, cubanos, ecuatorianos, salvadoreños, hondureños, mexicanos, nicaragüenses, panameños, paraguayos, peruanos, dominicanos, uruguayos, venezolanos y latinoamericanos de otras nacionalidades.

${ }^{41} \mathrm{En}$ «El derecho al voto de las personas extracomunitarias», del BOTELÍN DEL OBSERVATORIO PERMANENTE DE LA INMIGRACIÓN EN NAVARRA, cit. en n. 32, págs. 9 y 10, se recuerda que para las elecciones locales del 22 de mayo de 2011 que hubo agrupaciones políticas formadas solo o básicamente por inmigrantes pero que «los resultados constatan el fracaso de estas iniciativas» cuyos militantes, claro está, como hemos apuntado al hablar de la limitación al voto activo, solo pueden ser personas que ya han adquirido la nacionalidad española si no son ciudadanos de la UE. 
No responde a la pregunta o no considera que partido alguno se preocupe por estos temas alrededor del $40 \%{ }^{42}$.

El 46,3\% declaró que si las elecciones generales fueran mañana y estuvieran habilitados para votar en ellas elegirían al PSOE mientras que el 13,3\% dijo que lo haría por el PP. El 24\% no contestó, el 11,8\% votaría en blanco o no iría a votar y el $4.9 \%$ votaría por otros partidos. El principal bloque de argumentos para votar al PSOE está formado por los relacionados con la defensa de los derechos de los inmigrantes mientras que quienes se inclinan por el PP lo hacen por identificación con las ideas de este partido.

\section{El voto de los inmigrantes latinoamericanos en elecciones en España. La experiencia de las elecciones del 22 de mayo de 2011}

La participación de los ciudadanos latinoamericanos que podían haber estado habilitados para ejercer el derecho al voto en las elecciones locales celebradas el 22 de mayo de 2011 en virtud de los convenios pertinentes fue marginal básicamente por tres motivos según la encuesta estudiada y de acuerdo a valoraciones emitidas por distintas organizaciones que trabajan en temas de inmigración en España.

En primer lugar los mencionados convenios exigen que los ciudadanos que se acogen a ellos lleven residiendo en España de forma legal y sin interrupción al menos cinco años. Una exigencia a todas luces con escaso sentido si se considera que todos los países latinoamericanos que han suscrito estos convenios de reciprocidad de derecho al voto en elecciones locales tienen también suscritos con España, desde hace varias décadas, convenios de doble nacionalidad que, conforme la legislación española pertinente (el Código Civil, esencialmente), permiten a los citados ciudadanos latinoamericanos acogerse a los correspondientes convenios de doble nacionalidad residiendo de forma legal y sin interrupción durante, al menos, dos años. En consecuencia la mayor parte de ciudadanos en cuestión suele haberse acogido a los respectivos convenios de Doble Nacionalidad antes de que pasen cinco años de residencia en España.

El segundo motivo de la citada escasa participación es que para poder votar en los mencionados comicios locales el gobierno español

42 Cebrián, Juan Antonio, cit. en n. 28. El autor indica: «Las fuerzas políticas van a tener que cuidar su discurso en materia de inmigración pues los votos que se puedan ganar entre algunos nacionales enfadados con el fenómeno de la inmigración pueden perderse entre estos colectivos de inmigrantes que ahora votan». 
estableció la obligatoriedad de que los ciudadanos implicados se inscriban en el padrón electoral. Tal inscripción, además, se acompañó de un proceso engorroso para el que se necesitaba invertir al menos dos días de trámites. Esto constituyó un claro elemento disuasorio tal como señalaron en su momento diversas entidades del sector.

En tercer lugar la convocatoria para tal inscripción para ejercer el derecho al voto en elecciones locales así como la existencia en sí de los mencionados convenios de reciprocidad en materia de voto en elecciones locales no fueron lo suficientemente difundidas. Gran parte de la población implicada no tuvo conocimiento al respecto como, igualmente, subrayaron diversas entidades que trabajan en temas de inmigración en España.

Según la encuesta, ante el planteamiento «en relación al derecho al voto de los inmigrantes en las elecciones políticas españolas diría usted que...», casi la mitad de los encuestados respondió afirmando que desconocía que algunos inmigrantes -no nacionalizados como españoles, se entiende- tienen derecho al voto en España. El 4\% respondió que ningún inmigrante tiene derecho al voto.

La Resolución de 15 de octubre de 2010, de la Oficina del Censo Electoral (OCE), por la que se establecen los procedimientos y se aprueba el modelo de solicitud para la inscripción en el censo electoral de residentes en España de nacionales de países con acuerdos para las elecciones municipales ${ }^{43}$, establece que los concernidos recibirán una comunicación de la OCE para inscribirse en el censo pertinente tras haber obtenido sus datos del Registro Central de Extranjeros y de los padrones municipales. Y que «para solicitar la inscripción los interesados deberán completar la solicitud «en la forma que se requiera, firmarla y remitirla a la Delegación Provincial de la Oficina del Censo Electoral correspondiente y que la respuesta también podrá ser realizada conforme a los procedimientos de administración electrónica que se establezcan». También que «los extranjeros residentes en España que consideren que cumplen las condiciones establecidas podrán presentar personalmente las solicitudes de inscripción en el Ayuntamiento de residencia, en el impreso proporcionado por la Oficina del Censo Electoral, en cuyo caso el interesado deberá acreditar su identidad y el tiempo de residencia en España en la forma que se determine». Asimismo que «el tiempo de residencia legal en España requerido se deberá justificar con un certificado de residencia, expedido por la Comisaría de Policía, cuando no se 93128.

${ }^{43}$ BOE del viernes 5 de noviembre de 2010, Núm. 268, SEC. III, págs. 93124- 
pueda deducir de los datos de la fotocopia de la Tarjeta de identidad de extranjero, si esta fuera aportada». Igualmente se solicitaba que o bien el permiso de residencia estuviera vigente al momento de realizar la inscripción en el CERE o que se presentara un «certificado de residencia» que tardaba casi o más en expedirse que el plazo para poder apuntarse al censo ${ }^{44}$.

Dados los trámites evidentemente burocráticos a los que se sometió a los extranjeros concernidos y ante las reclamaciones pertinentes de los colectivos de inmigrantes y del propio PSOE, partido gobernante en aquellos momentos a nivel nacional, en primer lugar la OCE cedió ampliando el plazo de inscripción que, inicialmente, se había fijado según la citada Resolución entre «el 1 de diciembre del año 2010 y el 15 de enero de 2011». No obstante aún fueron miles los extranjeros que no pudieron inscribirse debido a la falta de información suficiente $^{45}$, a que para realizar los trámites debían ausentarse de sus puestos de trabajo en horas de oficina y a que en muchas ocasiones los funcionarios encargados de realizar las gestiones pertinentes carecían de formación e información suficientes y, en fin, a la serie de mecanismos burocráticos que se describen en las correspondientes resoluciones que dilataron y entorpecieron el proceso, tal como apuntaron diversas entidades ${ }^{46}$.

${ }^{44}$ Cebrián, Juan Antonio, cit. en n. 28, pág. 11.

${ }^{45}$ El FORO PARA LA INTEGRACIÓN SOCIAL DE LOS INMIGRANTES, en su informe La participación política de las personas inmigrantes, cit. en n. 13, p. 61 y 62, señala que «una de las lecciones del proceso electoral de 2011 y de la participación de los inmigrantes en él señala la necesidad de aplicar políticas de sensibilización, formación y empoderamiento desde ya y sin esperar a los comicios siguientes... No basta con declaraciones testimoniales ni con campañas ad hoc, ya sean las muy meritorias realizadas por las organizaciones sociales como la desarrollada con carácter institucional. En cuanto a la inscripción en el censo electoral, la publicación recuerda que los ciudadanos comunitarios «no tienen que volver a inscribirse para cada nuevo comicio».

Las modalidades de ejercicio del sufragio activo y pasivo por los ciudadanos comunitarios fueron aclaradas a través de la Directiva del Consejo 94/80/CE, de 19 de diciembre de 1994. La normativa se desarrolla a través de la Directiva 96/30/CE, de 13 de mayo de 1996, que amplía el sufragio a los nacionales de Austria, Finlandia y Suecia; la Directiva de 23 de septiembre de 2003, para la República Checa, Estonia, Chipre, Lituania, Hungría, Malta, Polonia, Eslovenia y Eslovaquia; y la Directiva 2006/106/CE de 20 de noviembre de 2006, relativa a Bulgaria y Rumania.

${ }^{46}$ CeBrián, JuAn Antonio, cit. en n. 28, p. 20. El autor indica: «Según ha sido denunciado por numerosos actores socioeconómicos, el proceso de inscripción en el CERE ha tenido defectos de fondo y forma que han obstaculizado una participación importante de los residentes extranjeros en la constitución de los gobiernos locales» en las elecciones del 22 de mayo de 2011. 
Estos hechos fueron la causa de que apenas 5,133 latinoamericanos se pudieran inscribir en el citado $\mathrm{CERE}^{47}$ cuando desde la Administración se enviaron 350.287 cartas de convocatoria para tal inscripción y, más aún, cuando se hablaba de un universo de alrededor de 800.000 personas $^{48}$ que la Administración no contabilizó en su totali$\mathrm{dad}^{49}$. Confirma que habría habido un número mucho mayor de inscritos en el CERE el elevado número de reclamaciones a la OCE ${ }^{50}$

Asimismo, más allá de la coyuntura burocrática, los acuerdos de reciprocidad en materia de sufragio en elecciones municipales establecen normas complejas que la Resolución de 15 de octubre de 2010 de la OCE resumió: «Los Canjes de Notas constitutivos de Acuerdo entre el Reino de España y la República de Chile, la República de Colombia, la República del Ecuador, la República de Paraguay, la República del Perú, y de Nueva Zelanda, sobre participación en las elecciones municipales de los nacionales de cada país residentes en el territorio del otro, establecen los siguientes requisitos: 1 . Los ciudadanos nacionales de los países citados en el párrafo anterior podrán ejercer el derecho de sufragio activo en las elecciones municipales. 2. Deberán estar en posesión de la correspondiente autorización de residencia en España. 3. Deberán haber residido en España, legal e ininterrumpidamente durante, al menos, los cinco años anteriores a su solicitud de inscrip-

${ }^{47}$ Según la Oficina del Censo Electoral http://www.ine.es/jaxi/tabla.do?path=/t44/ p06/a2011/10/\&file $=0310$.px \&type $=$ pcaxis $\& \mathrm{~L}=0$ se inscribieron 25,668 ecuatorianos, 12,632 colombianos, 5,897 peruanos, 5.042 bolivianos, 1,249 chilenos y 645 paraguayos.

${ }^{48}$ Según el INSTITUTO NACIONAL DE ESTADÍSTICA http://www.ine.es/prensa/ np833.pdf, a 1 de julio de 2013 -y a falta de consolidar los resultados sobre chilenos y paraguayos- residían en España 240.735 ecuatorianos, 194.182 colombianos, 144.665 bolivianos y 96.220 peruanos.

${ }^{49}$ CEBRIÁN, Juan Antonio, cit. en n. 28, p. 8. El autor señala: «Ha sido muy llamativa la lentitud con la que se ha llevado a cabo el registro de los posibles votantes. Es un hecho notorio la falta de información y el desconocimiento por parte del extranjero (sobre todo del extracomunitario) de las condiciones materiales y formales a cumplir para poder ejercitar el derecho de sufragio. Si no se promueve y desarrolla la inscripción de los extranjeros en los padrones electorales de nada sirven las campañas para que vayan a votar».

${ }^{50} \mathrm{En}$ "El derecho al voto de las personas extracomunitarias», del BOLETÍN DEL OBSERVATORIO PERMANENTE DE LA INMIGRACIÓN EN NAVARRA, cit. en n. 32, pág. 9, se apunta: «Un dato con confirma la voluntad de las personas extranjeras por tener participación política es el elevado número de reclamaciones a la Oficina del Censo Electoral con carácter previo a las elecciones, sobre todo si tenemos en cuenta el tamaño del CERE y lo comparamos con el del CER (Censo de Electores Residentes) y el del CERA (Centro Electoral de Residentes Ausentes), ambos para personas de nacionalidad española. Las reclamaciones del CERE supusieron el 1,64\% sobre el total de ese Censo, mientras que las proporciones sobre el CER y el CERA fueron del $0,04 \%$ y $0,2 \%$, respectivamente». 
ción en el censo electoral. 4. Ejercerán el derecho de voto en el municipio de su residencia habitual, en cuyo padrón deberán figurar inscritos. 5. La inscripción en el censo electoral de extranjeros residentes en España, requisito indispensable para poder ejercer el derecho de sufragio, se hará a instancia de parte. Esta instancia se presentará en el Ayuntamiento en cuyo padrón municipal figure inscrito. El plazo de inscripción se realizará para cada elección».

En este contexto, al señalar los motivos por los que no realizaron la mencionada inscripción el $22 \%$ de los encuestados indicó que fue por falta de interés pero muy de cerca el segundo motivo esgrimido es la «falta de información» (20,3\% de los encuestados señalaron este motivo). Otros motivos fueron el no estar habilitado para ejercer el derecho $(18,6 \%)$, el no tener una nacionalidad habilitante $(17,4 \%)$, el carecer de documentación pertinente $(9,3 \%)$, la falta de tiempo $(4,2 \%)$ y el cambio de domicilio (2,5\%). La falta de interés está ligada con la insuficiencia de información y de campañas particularmente dirigidas al colectivo.

\section{CONCLUSIONES}

El reconocimiento de la titularidad y el ejercicio de derechos civiles y políticos de los inmigrantes resulta clave en los procesos de integración para reforzar sociedades cohesionadas. En el caso español, este reconocimiento de derechos a favor de los residentes latinoamericanos resulta en un círculo virtuoso como modelo de integración y cohesión pues aprovecha las facilidades de integración diríase innatas de los latinoamericanos en España gracias a los ejes comunes hispano-latinoamericanos (lengua, cultura, etc.). El legislador ha tomado buena nota de ello desde hace décadas llevando a cabo convenios como los de Doble Nacionalidad que España mantiene sobretodo con países latinoamericanos.

Al hablar del reconocimiento de la titularidad y el ejercicio del derecho al voto de los extranjeros en España, diversos autores apuntan que sería deseable reformar el artículo $13 \mathrm{CE}$ para que no se exija reciprocidad pues así se está dejando fuera del esquema a ciudadanos de países con carencias democráticas y, particularmente, a los ciudadanos marroquíes, con una presencia numerosa en España. Sin ánimo de querer marginar a colectivo alguno, está claro que hoy por hoy este punto no afecta a la mayor parte de países latinoamericanos que, también en este marco, presentan mayores probabilidades de integración. 
El voto de los latinoamericanos residentes en España será decisivo en las elecciones venideras. Si se considera únicamente a aquellos que aún no se han acogido a los convenios de Doble Nacionalidad que sus países mantienen con España pero cuyos Estados de origen han firmado con España convenios de reciprocidad en materia de sufragio, estamos hablando de un universo formado por alrededor de un millón de personas.

El sentido común y los anuncios que se han hecho en tal sentido permiten señalar que las Administraciones Públicas, honrando los convenios internacionales pertinentes suscritos por España, depurarán las deficiencias que existieron al legislar sobre los reglamentos y demás disposiciones legales de aplicación práctica de los convenios de reciprocidad en materia de sufragio. Asimismo resulta imperativo que se subsanen los numerosos defectos de discrecionalidad y falta de información por parte de los funcionarios que deben aplicar tal normativa de cara a los ciudadanos concernidos, defectos que se sucedieron al registrar en el CERE a los ciudadanos correspondientes.

Como acciones concretas, las Administraciones Públicas tienen el reto de efectuar campañas de información y sensibilización ante los nuevos electores. Igualmente las organizaciones sociales y los expertos en la materia apuntan la necesidad de que el CERE esté abierto de forma permanente a los ciudadanos no comunitarios de la misma manera que se mantiene un sistema de inscripción permanente para los comunitarios. Por último es recomendable que se cuente con la opinión de las organizaciones de inmigrantes más representativas a la hora de redactar la legislación pertinente de una manera eficaz y contando con aquellas entidades realmente representativas de los colectivos concernidos pues, si bien se ha solicitado el consejo de algunas entidades para redactar leyes como la llamada Ley de Extranjería, no parece que se haya tomado en cuenta la opinión sustancial de estas organizaciones habida cuenta, claro está, de que su intervención es meramente consultiva más no vinculante.

En todo caso está probada y desarrollada legalmente la voluntad política de incorporar a los procesos legislativos, al menos a los municipales, a los ciudadanos de países principalmente latinoamericanos. Tal marco legal es por ahora general -convenios internacionales y reglamentes de aplicación- por lo que el legislador tiene ante sí la tarea de desarrollar plenamente la materia en el resto de órdenes legislativos inferiores (resoluciones, disposiciones, etc.) de modo que los ciudadanos concernidos puedan ejercer el derecho que les conce- 
den los mencionados convenios internacionales de manera de efectiva de forma cualitativa y cuantitativa.

Otro tema es el del derecho al voto pasivo. Un derecho, el del voto pasivo, del que sí gozan los españoles en países con los que existe convenio de reciprocidad en materia de sufragio, como Perú. Y del que, por otra parte, sí gozan en España los ciudadanos del resto de países comunitarios. Un tema sobre cuya viabilidad se pronuncian de forma favorable los expertos en la materia sustentándose en la $\mathrm{CE}$, cuyo artículo 13 habla de derecho al sufragio activo y pasivo.

Diferente es el tema del reconocimiento de la titularidad y el ejercicio del derecho al voto en elecciones generales para lo cual, como apuntan los autores en los últimos tiempos, se requeriría una reforma más profunda de la legislación vigente empezando por el artículo 13 $\mathrm{CE}$ que únicamente habla de «elecciones municipales». Ahondando un poco más en este sentido, y admitiendo como válida la premisa anteriormente señalada, no está de más apuntar que, gracias a los convenios de Doble Nacionalidad que España mantiene suscritos con la mayor parte de países latinoamericanos, podemos hablar ya de millones de latinoamericanos de origen que, naturalizados como españoles, ya están votando en todo tipo de elecciones en España. 
